\section{Kastamonu Eğitim Dergisi Kastamonu Education Journal}

Mayıs 2019 Cilt:27 Sayı:3

kefdergi.kastamonu.edu.tr
Başvuru Tarihi/Received: 03.01.2018

Kabul Tarihi/Accepted: 16.07 .2018

DOI: $10.24106 /$ kefdergi. 2524

\title{
Üniversite Öğrencilerinin Öz-Anlayışlarının, Bağlanma Stilleri ve Ílişki Durumları Bakımından İncelenmesi
}

\section{An Investigation of the Self-Compassion of University Students in Terms of Attachment Styles and Relationship Status}

\section{Öz}

\author{
Nur BAŞER BAYKAL ${ }^{1}$, Tuba KALAY USTA², Hale Nur KILIÇ MEMUR³ ${ }^{3}$ Ahmet ŞiRiN ${ }^{4}$
}

Bu çalışmanın amacı, İstanbul ilindeki çeşitli üniversitelerde öğrenim gören öğrencilerin öz anlayış düzeyleri ile yakın ilişkilerdeki bağlanma stilleri arasındaki ilişkiyi ortaya koymaktır. Ayrıca çalışmada, öz anlayış ve bağlanma düzeylerinin çeşitli demografik durumlara göre farklılaşıp farklılaşmadığı incelenmiştir. Araştırma ilişkisel tarama modelinde hazırlanmıştır. Araştırmanın örneklem grubu, tesadüfi oranlı küme örnekleme yöntemiyle seçilen 366 üniversite öğrencisidir. Araştırmada, Öz Anlayış Ölçeği, Yakın illişkilerde Yaşantılar Envanteri ve araştırmacının hazırladığı kişisel bilgi formu kullanılmıştır. Yapılan araştırma sonucunda öğrencilerin öz anlayış düzeyleri ile kaygılı ve kaçınmalı bağlanma stilleri arasında negatif yönde anlamlı bir ilişki bulunmuştur. Ayrıca, ilişki durumuna göre kişilerin öz anlayış düzeyleri farklılık göstermiştir.

Anahtar Kelimeler: öz anlayış, bağlanma, yakın ilişkilerde yaşantılar, kaygılı bağlanma, kaçınmalı bağlanma

\section{Abstract}

The aim of this study was to reveal the relationship between the self-compassion and attachment of the university students. It was examined whether the levels of self-compassion and attachment differ according to the demographic variables. The research was prepared in a screening model. The study sample group consisted of 366 university students selected randomly by cluster sampling method. In this study, Self-Compassion Scale, the Experiences in Close Relationships Inventory and the personal information form prepared by the researcher was administrated. According to the findings, it was found that there was a significant negative correlation between students' self-compassion levels and anxious and avoidant attachment. On the other hand, self-compassion levels of students differed according to the relationship status.

Keywords: self-compassion, Attachment, Experiences in Close Relationships, Anxious Attachment, Avoidant Attachment

1. Bartın Üniversitesi, Edebiyat Fakültesi, Psikoloji Bölümü, Bartın, Türkiye; https://orcid.org/0000-0002-9737-3473

2. Biruni Üniversitesi, Eğitim Fakültesi, İstanbul, Türkiye; https://orcid.org/0000-0003-3628-8432

3. Marmara Üniversitesi, Atatürk Eğitim Fakültesi, Eğitim Bilimleri Bölümü, İstanbul, Türkiey; https://orcid.org/0000-0002-8160-0571

4. Marmara Üniversitesi, Atatürk Eğitim Fakültesi, Eğitim Bilimleri Bölümü, İstanbul, Türkiye; https://orcid.org/0000-0003-1582-0493

Atıf / Citation: Başer Baykal, N., Kalay Usta, T., Kılıç Memur, H.N., ve Şirin, A. (2019). Üniversite öğrencilerinin öz-anlayışlarının, bağlanma stilleri ve ilişki durumları bakımından incelenmesi.Kastamonu Education Journal, 27(3), 1023-1032. doi:10.24106/kefdergi.2524 


\section{Extended Summary}

Self-compassion means rather than criticizing oneself rigorously and identifying oneself with negative experiences, accepting negative events and being receptive to their own sufferings and mistakes. To have self-compassion is to protect oneself as much as possible from the painful situations and to take measures against negativity.

Attachment is one of the factors that influence the relationship that people establish with people they are close to. This relationship is defined as a deep emotional bond that meets the individual's need for belonging and trust. There are mainly two types of attachment styles, which are secure and insecure. If a person has secure attachment style, it is probable to have positive attitudes in interpersonal and intrapersonal relationships. Self-compassion also has a positive effect on dealing with interpersonal problems; therefore, attachment style can be a predictive factor for self-compassion.

Purpose: The aim of this study is to reveal the relationship between the self-compassion and attachment of the students in the state and private universities in Istanbul. It was also aimed to examine whether the levels of self-compassion and attachment differ according to sex, age, the number of sibling, economic status, relationship status, academic achievement and psychological assistance.

Method: This section covers research model, data collection and data analysis parts.

Research Model: The model of this study is screening model, which is one of the most common methods used for analysing the research results. The purpose of a relational analysis is to reveal the relationship between different factors.

Data Collection: The population of the research was determined as students who attended state and private universities in Istanbul in the academic year of 2017-2018. The sample group consists of 366 students selected randomly from Istanbul Yıldız Technical University, Istanbul Sabahattin Zaim University and Biruni University in 20172018 academic year. In order to collect data for the sampling group, the Self-Compassion Scale, the Experiences in Close Relationships Inventory and the personal information form, prepared by the researcher, were given.

Findings: In accordance with the results of this study, there was a significant negative correlation between students' self-compassion levels and anxious and avoidant attachment. Also, according to the relationship status, the level of self-compassion differed. People who have a relationship have a lower level of self-compassion than people who do not have a romantic relationship. In addition, avoidant attachment scores of individuals who have a romantic partner are lower than people who do not have a romantic partner.

Discussion: This study is important to investigate the relationship between self-compassion and attachment in close relationships and to investigate how the relationship differs according to which variables. This research can help to psychological counselors and psychologists at the point of intervention to increase the level of self-compassion of the students because our research results and literature show that there is a strong relationship between self-compassion and attachment styles via providing functional and concrete information. In the light of this research, experts in this area can create programs, which aim to increase self-compassion.

When the literature is examined, it is determined that there is very little work on the concept of self-compassion in the field of guidance and psychological counseling, and that the number of studies conducted to investigate the relationship between attachment and close relationships is inadequate. For this reason, this research is important in the sense that it is a study, which considers the relationship between self-compassion and attachment in close relationships. This research is also important in terms of contributing to different studies about the self-compassion that can be done in the future and attachment styles in close relationships and presenting new perspectives. 


\section{Giriş}

İnsan olmak, doğası gereği acı çekmeyi ve hayatla olan mücadelede zorlanmayı getirebilir (Sümer, 2008). Kişinin olumsuz duygularını ve kendisini yargılamadan, yaşadıklarını insan olmanın bir parçası ve insan olmanın ortak deneyimi olarak görmesi kişinin acısını hafifletecek ve sorunlarıyla baş edebilmesini sağlayacaktır. Bunu yapabilme yeteneği kişinin öz anlayış düzeyine bağııdır (Leary, Tate, Adams, Batts Allen ve Hancock, 2007; Neff, 2003a).

Öz anlayış kavramı Budist felsefe temelli bir kavramdır. Doğu kökenli olan bu kavram psikoloji alanında son zamanlarda önem kazanmış ve üzerine çalışmalar yapılmaya başlanmıştı (Akın, 2009). Öz anlayış, kişinin kendisini sert bir şekilde eleştirmesi yerine, kendi acılarına ve yanlışlarına karşı anlayışı olması ve bu acılarla kendini tanımlamak ve özdeşleştirmek yerine, onların farkında olarak kabullenmesi demektir (Neff, 2003a; Neff, Kirkpatrick ve Rude, 2007). Aynı zamanda, öz anlayış sahibi olmak, kişinin elinden geldiğince kendini acı verecek durumlardan koruması ve olumsuzluklara karşı önlem alması anlamına gelmektedir. Bu da öz anlayışın yükselmesiyle kişinin kendini koruyacak ve iyi hissetmesini sağlayacak davranışları daha fazla göstereceği anlamına gelmektedir (Neff, Hsieh ve Dejitterat, 2005). Öz anlayış düzeyi yüksek olan kişiler problemlerinin ve eksikliklerinin farkındadır; fakat kendilerine kat, acımasız ve eleştirel bir tutumla yaklaşmak yerine anlayış ve şefkatle yaklaşırlar. Bu şekilde, öz anlayış, bireylerin yaşamlarında olumsuz giden durumlarda koruyucu bir görev üstlenerek; bu dönemleri daha kolay geçirmelerini ve olumlu duyguları yakalamalarını sağlar (Leary ve ark., 2007).

Neff (2003a, 2003b) öz anlayış kavramını üç ana faktör ile açıklamıştır: Öz şefkat (self-kindness), ortak paydaşım (common humanity) ve bilinçli farkındalık (mindfullness). Bunlardan ilki olan öz şefkat kavramı kendini suçlamanın ve eleştirmenin tam tersidir (Neff, Kirkpatrick ve Rude, 2007). Kişiler hayatlarında problem olduğunda kendilerini suçlama eğilimindedirler; fakat öz şefkat sahibi olanlar kendilerine karşı ağır eleştirilerden kaçınarak olumsuz olayları değerlendirirken daha anlayışlı ve pozitif bir tarzda yaklaşırlar (Neff, 2003a; Neff 2003b; Neff, Hsieh ve Dejitterat, 2005). İkinci ana öğe olan ortak paydaşım, kişinin acılarını diğer insanların da anlayabildiğini, onların da hissedebildiğini bilmesiyle beraber yalnızlık ve izolasyon hislerine kapılmasının engellenmesini sağlar (Germer, 2009). Ortak paydaşım olduğunu düşünen ve bunu kendilerinde hisseden kişiler olumsuz duygular yaşadıklarında veya hayal kırıklığına uğradıklarında kendilerini farklı ve izole hissetmekten ziyade, diğer bireylerin de bunları yaşadıklarını ve olumsuz tecrübe ve duyguların da ortak değerler olduğunu düşünürler (Neff, 2003a). Böylece baş etmeleri kolaylaşır ve hem kendilerine hem de diğerlerine karşı daha şefkatli davranırlar (Özyeşil, 2011). Öz anlayışı oluşturan üçüncü ana öğe ise bilinçli farkındalıktır. Bilinçli farkındalık, bireyin acı veren durumlarla karşılaştğında yoğun şekilde sorunun içine girerek odaklanmak yerine sorunun farkına varmasını ifade eder (Germer, 2009). Böylece önyargı azalır ve olumsuz öz eleştiri hafifleyerek öz şefkat $\operatorname{artar}$ (Neff, 2003a). Kişinin olumsuz duygularla baş edebilmesi için farkındalık çok önemlidir ve diğer iki öğeyi (öz şefkat ve ortak paydaşlık) de direkt olarak etkiler (Sümer, 2008).

Öz anlayışın yaşam doyumu, depresyon, anksiyete, psikolojik iyi oluş gibi kavramlarla ilişkisine bakılmıştır; fakat kişiler arası ilişkilerle olan ilişkisini incele-yen çok az çalışma vardır (Neff ve Beretvas, 2013). Halbuki, öz şefkatin ve şefkatli ilişkilerin, stres hormonlarının etkisini azalttğı, beynin kimyasallarında değişiklik oluşturarak bağışıklık sistemini güçlendirdiği bilgisi (Gilbert, 2009) öz anlayış ve ilişki arasında bağlantı olabileceğini göstermektedir. Özyeşil (2011) çocukluk döneminde duygusal bir üzüntü yaşamış olan kişilerin öz anlayış puanlarının yaşama-yanlara göre düşük olduğunu bulmuştur. Bu bulgu da geçmiş çocukluk yaşantılarının da öz anlayış üzerinde etkili olabileceğini göstermektedir. Gilbert (2009)'a göre öz anlayış, limbik sistemle ilişkili olan tehdit sisteminin etkinliğini azaltarak bağlanma ve güven duygularını aktive etmeye yönelik işlev görür. Bu sebeple öz anlayış ve kişiler arası bağlanma çalışılarak aradaki ilişkinin ortaya konması amaçlanmaktadır. Bunun için öncelikle bağlanmanın tanımına ve kişiler arasındaki önemine değinmek faydalı olacaktır.

Bağlanma, kişinin yakın olduğu insanlarla kurduğu ilişkiyi etkileyen faktörlerden biridir. Bu ilişki bireyin ait olma ve güven ihtiyacını karşılayan derin duygusal bağ olarak tanımlanır (Bowlby, 1969). Bağlanma teorisine göre, bebekleri temsil eden üç bağlanma şekli vardır: güvenli, kaygılı ve kaçınmalı. Bu bağlanma stillerinin ebeveynlerin bakım verici niteliklerinin çeşitliliği sonucu olduğu düşünülmektedir. Hassas ve duyarlı bakıcılar, sıkıntılı durumlarda kendilerini rahatlatma becerisi olan ve bakıcısıyla kurduğu güvenli bağdan emin olan bebekler yetiştirirler. Buna karşılık, tutarsız bakıılar, bağlanma şekillerinin bulunup bulunmadığı konusunda kararsız kalan kaygılı bebeklerin yetişmesine neden olurlar ve bu bebekler sıkıntı yaşadıklarında yüksek duygusal uyarılma gösterirler. Reddeden bakıcılar ise, bağlanma figürleriyle rahat hissetmeyen, sessiz duygusallıkla tepki veren ve sıkınt yaşadıklarında bakım veren kişiye yönelmeyen kaçınmacı bebeklerin yetişmesine sebep olurlar (Bretherton, 1985; Cassidy, 1994). Shaver ve Hazan’a (1987) göre kaygıı bağlanma; diğerleriyle yakın olma isteği ve terk edilme endişesi ile dışavurum gösterirken, kaçınmalı bağlanma; yakınlık korkusu ve diğerlerine olan bağımlııktan kaçınma eğilimi ile kendini gösterir. 
Bağlanmanın, kişilerarası ilişkilerdeki yerini inceleyen çalışmalar, bağlanma teorilerinin gündelik hayatta ne kadar etkin olduğunu gösterir niteliktedir. Örneğin, güvensiz yetişkin bağlanma boyutları (kaygılı ve kaçınmalı bağlanma) ve romantik ilişki kalitesinin, bilişsel, duygusal ve davranışsal göstergeleri arasındaki ilişkiyi özetleyen; ayrıca kaygı ve kaçınmanın ilişki kalitesi üzerindeki farklı etkilerini inceleyen bir çalışmada sonuçlar, hem kaygı hem de kaçınmanın ilişki kalitesinin bilişsel, duygusal ve davranışsal yönlerini olumsuz etkilediği doğrulanmıştr. Kaygı ile karşılaştrıldığında, kaçınma, ilişkilerdeki genel memnuniyet, bağlılık ve genel destek ile daha olumsuz bir ilişki içinde bulunmuştur. Bununla birlikte, kaygının, ilişkilerdeki genel çatışma ile olumlu bir ilişki içinde olduğu gözlenmiştir (Li ve Chan, 2012). Arkadaşlık ve romantik ilişkilerdeki stres faktörleri ile depresyon arasındaki ilişkiyi gözlemleyen bir çalışmada, yüksek kaçınmalı ve kaygılı bağlanma düzeyleri, yüksek depresyon düzeyi ile ilişkili çıkmıştır. Araştırma sonuçları, romantik ilişkilerdeki stres faktörleri ile depresyon arasındaki ilişkide kaygılı bağlanmanın aracı bir ilişkisi olduğunu göstermiştir (Chow ve Ruhl, 2014). Bir başka çalışmanın bulgularına göre, her iki yetişkin bağlanma boyutu (kaçınmalı ve kaygılı) romantik ilişkilerde, çatş̧ma çözme davranışları ve ilişki doyumunun öngörücüleridir. Bu çalışma, ben ve diğerleri hakkında olumlu algılamalara sahip olanların, her iki tarafin endişelerini de giderecek şekilde çatışma çözme davranışlarını benimseme şansının yüksek olduğunu ortaya koymuştur (Shi, 2003).

Üniversite öğrencileri ile yapılan bir çalışmada elde edilen bulgular, bireylerin ne kadar kaçınmalı davranırlarsa, yakın ilişkide bulunduğu kişiler tarafindan (romantik ilişki veya yakın arkadaş) değiştirmeleri istenen davranışlarını, o kadar az geliştir-meye yönelik davrandıklarını göstermektedir (Zhang, 2012). Üniversite öğrencileri arasında yapılan bir başka çalışmada ise, kaçınmalı bağlanma düzeyi yüksek olan kişilerin, diğer kişileri hâkimiyet, dostça itaatkârlık ve dostça egemen sahibi görme eğiliminin daha düşük olduğunu ortaya koymuştur (Mallinckrodt ve Chen, 2004).

Bağlanma şekillerinin farklı değişkenlerle ilişkisine bakan çalışmalar incelendiğinde öncelikle yaş faktörü göze çarpmaktadır. 18-70 yaş aralığındaki internet kullanıcıları arasında kaçınmalı ve kaygılı bağlanma düzeylerini inceleyen bir çalışmada, kaygılı bağlanma, genç yetişkinlerde en yüksek, orta yaşta ve daha yaşlı yetişkinlerde en düşük bulunmuştur. Kaçınmalı bağlanmada yaş farkı pek fazla görülmemekle birlikte, daha genç ve daha yaşlı yetişkinlerle kıyaslandığında, orta yaş yetişkinlerde daha yüksek çıkmıştr. Yine aynı çalışmada hem kaçınmalı hem de kaygılı bağlanma düzeyi, partneri olan katılımcılara oranla, her yaş grubundan bekâr katlımcılarda daha yüksek çıkmıştır. Ayrıca, kadınların genellikle erkeklerden daha fazla kaygılı ve kaçınmalı bağlanma düzeyine sahip olduğu görülmüştür (Chopik, Edelstein ve Fraley, 2013). Bağlanma şekillerinin, ileride yetiştirilecek çocuklar üzerinde de etkisi olduğunu gösteren çalışmalar mevcuttur. Örneğin bir çalışmada, kaçınma konusunda yüksek puan alan ebeveynlerin, sıkınt yaşayan çocuklarına daha az duyarlı davrandığı gözlenmiştir (Edelstein ve ark., 2004).

Yukarıdaki bilgiler ışı̆̆ında, bu çalışmada öz anlayış ve yakın ilişkilerde bağlanma arasındaki ilişkinin incelenmesi ve bu ilişkinin hangi değişkenlere göre farklılık gösterdiğinin araştıııması amaçlanmıştı. Literatür incelendiğinde rehberlik ve psikolojik danışmanlık alanında öz anlayış kavramına dair çok az çalışmanın olduğu ve yakın ilişkilerde bağlanma ile arasındaki ilişkinin incelenmesine yönelik yeterli sayıda araştırmanın yapılmadığı tespit edilmiştir. Bu nedenle, bu araştrma öz anlayış ve yakın ilişkilerde bağlanma arasındaki ilişkiyi ele alan bir çalışma olması anlamında önem taşır. Bu amaçlar göz önüne alınarak çalışmada "öğrencilerin öz anlayış ve bağlanma stilleri arasında ilişki var mıdır?" ve "öğrencilerin bağlanma stilleri öz anlayış düzeylerini yordamakta mıdır?" sorularına yanıt aranmıştır. Ayrıca, öz-anlayış düzeyinin ve yakın ilişkilerdeki bağlanma stillerinin kişisel bilgi formunda yer alan yaş, cinsiyet, kardeş sayısı, ekonomik durum, ilişki durumu, akademik başarı ve psikolojik yardım alma durumları ile ilgili değişkenlere göre farklılaşıp farklılaşmadığı araştrılmıştır.

\section{Yöntem}

Bu kısımda araştırmanın modeli, evren ve örneklem, veri toplama araçları, veri toplama süreci ve verilerin analizi ile ilgili açıklamalara yer verilmiştir.

\section{Araştırmanın Modeli}

Araştırma, İstanbul'da bulunan devlet ve vakıf üniversitelerinde eğitim gören üniversite öğrencilerinin öz-anlayış ve bağlanma stilleri arasındaki ilişkiyi incele-meyi hedeflemektedir. Bu sebeple çalışma modeli olarak ilişkisel tarama modeli seçilmiştir.

Iliş̧kisel tarama modeli iki ya da daha fazla değişken arasındaki değişimi ve bu değişimin derecesini tanımlamak üzere kullanılan bir araştırma modelidir (Neuman, 2007). Tarama modelinin kullanılmasındaki temel amaç; örneklemden toplanan bilgilerle evrenin genelindeki görüşleri ve tutumları açıklamaktır (Creswell, 2013). 


\section{Evren ve Örneklem}

Araştırmanın evreni 2017-2018 eğitim-öğretim yılında İstanbul ilindeki devlet ve vakıf üniversitelerinde öğrenim gören öğrenciler olarak belirlenmiştir. Örneklem grubu ise 2017-2018 eğitim-öğretim yılında İstanbul ilindeki Yıldız Teknik Üniversitesi, İstanbul Sabahattin Zaim Üniversitesi ve Biruni Üniversitesinden tesadüfi orantısız küme örnekleme yöntemiyle seçilen 359 öğrenciden oluşmaktadır.

\section{Veri Toplama Araçları}

Araşttrmada, Öz-Anlayış Ölçeği ve Yakın Illişkilerde Yaşantılar Ölçeği (YiYE) kullanılmıştr. Ölçeklerin psikometrik özelliklerine ilişkin bilgiler sırasıyla aşağıda yer almaktadır.

\section{Öz Anlayış Ölçeği}

Öz-Anlayış Ölçeği (Self Compassion Scale) kişilerin öz şefkat, bilinçli farkındalık ve paylaşımlarının bilincinde olma alt boyutlarını inceleyerek öz anlayış değerlerine ulaşmak amacıyla Neff (2003) tarafindan geliştirilmiştir. 26 maddeden oluşan Self Compassion Scale (SCS) 6 alt ölçekten oluşmaktadır: öz-yargılama, öz-nezaket, ortak insanlık, bilinçlilik, izolasyon ve aşırı-özdeşleşme. Self Compassion Scale (SCS) bütünü için iç tutarlık katsayısı (Cronbach alfa) .92 bulunmuştur (Neff, 2003). Alt ölçeklerinin iç tutarlıkları, öz-nezaket alt ölçeği için .78, öz-yargılama alt ölçeği için . 77, ortak insanlık alt ölçeği için .80, izolasyon için .79, bilinçlilik için .75 ve aşırı özdeşleme için .81 olarak belirtilmiştir (Neff, 2003). Aynı şekilde ölçe-ğin test tekrar testi bütünü için .93; alt ölçekler için ise sırayla $.88, .88, .80, .85, .85, .88$ olarak verilmiştir (Neff, 2003). Katılımcılar ölçekte bulunan 26 madde ile ilgili olarak ne sıklıkla hareket ettiklerini 5li likert tipi ölçekte derecelendirerek ölçeği tamamlarlar. Ölçekte 1 puan vermek "Hemen hemen hiçbir zaman" ve 5 puan ise "Hemen hemen her zaman" anlamına gelmektedir (Neff, 2003). Katlımcılar 1-5 arası derecelendirme yaparak ne kadar sıklıkla bu durumlar içinde olduklarını belirtirler. Ölçekten yüksek puan almak öz anlayışın yüksek olduğunu ve düşük puan almak ise öz anlayışın düşük olduğunu gösterir.

Ölçeğin Türkçe uyarlaması ve geçerlik-güvenirlik çalışması Deniz, Kesici ve Sümer tarafindan 2008 yılında yapılmıştır. Bu uyarlamada orijinalinden farklı olarak ölçeğin tek boyutlu bir yapı gösterdiği bulunmuştur. Ayrıca; Deniz, Şahin ve Sümer (2008) madde toplam korelasyonunda .30'un altında olan 2 tane maddeyi (1. madde ve 22. madde) ölçekten çıkarmışlar ve Türkçe ölçeği 24 maddelik bir ölçek haline getirmişlerdir. Bu uyarlanan ölçeğin (Öz Anlayış Ölçeği) iç tutarlık katsayısı .89 ve test-tekrar test korelasyonu .83 olarak bulunmuştur (Deniz, Şahin ve Sümer, 2008). Ölçeğin ölçüt bağlantılı geçerliğini ölçmek için benlik saygısı, yaşam doyumu, pozitif duygu ve negatif duygu ile arasındaki ilişkiye bakılmıştr. Bu ölçeklerle olan korelasyonu sırasıyla .62, .45, .41 ve .48 olarak tespit edilmiştir (Deniz, Şahin ve Sümer, 2008).

\section{Yakın ilişskilerde Yaşantılar Ölçeği (YiYE)}

Yakın İlişkilerde Yaşantılar Ölçeği (YYYE) 1998 yılında Brennan, Clark ve Sha-ver tarafindan yetişkin bağlanma türlerini ölçmek amacıyla geliştirilmiştir. Ölçeğin amacı yakın ilişkilerde yaşanan kaygı ve yakın ilişki yaşanan kişiden kaçınma boyutlarını belirleyerek bağlanma biçimini ölçmektir (Brennan, Clark ve Shaver, 1998). Kaygı alt boyutunda 18 madde ve kaçınma alt boyutunda 18 madde olmak üzere; ölçeğin toplamda iki alt boyutu ve 36 maddesi bulunmaktadır. Katılımcılar her maddenin kendilerini ne kadar tanımladığını 7 dereceli Likert tipi ölçek üzerin-den belirlemektedirler (1=Beni hiç tanımlamıyor, 7= Beni tamamıyla tanımlıyor). Ölçekte kaygı boyutundan yüksek puan almak, kaygılı bağlanmayı gösterirken düşük puan almak kaygılı bağlanmanın az olduğu anlamına gelmektedir. Yine aynı şekilde kaçınma puanının artması kişinin kaçınmalı bağlanmalı yapısına işaret eder-ken, kaçınma alt puanının düşmesi kaçınmalı bağlanma stilinin baskın olmadığını göstermektedir (Brennan, Clark ve Shaver, 1998). Kaçınmalı ve kaygılı bağlanma biçimlerini ölçmeye ek olarak, puanlar arası sınıflandırma yapılarak ölçek korkulu, saplantılı, kaçınmalı ve güvenli bağlanma ile ilgili de bilgi verebilir. Her iki alt boyuttan düşük puan alanlar güvenli, her iki alt boyuttan da yüksek puan alanlar ise korkulu olarak sınıflandırılır. Ayrıca, kaygı boyutundan düşük kaçınma boyutundan yüksek alanlar kaçınmalı ve kaygı boyutundan yüksek kaçınma boyutundan düşük alanlar ise saplantlı olarak belirlenebilir.

Ölçek, Sümer (2006) tarafindan çevrilmiş ve faktör analizi çalışmaları yapılmıştr. Çalışmalar sonucunda Sümer (2006) ölçeğin iki faktörlü (kaygı ve kaçınma) olduğunu belirtmiştir. Kaygı alt faktörün iç tutarlık katsayısı (Cronbach alfa) 86 ve kaçınma alt faktörünün iç tutarlık katsayısı (Cronbach alfa) . 90 olarak elde edilmiştir. Ölçekte ters olan maddeler vardır, bu maddelerin ters puanlanması gerekmektedir (3., 15., 19., 22., 25., 27., 29., 31., 33. ve 35. maddeler).

\section{Verilerin Toplanması}

Çalışmada ölçekler, üniversitelerde araştırma örneklemine araştırmacı tarafindan uygulanmıştır. Uygulamadan önce öğrencilere araştırmanın önemi ve katkıları hakkında bilgi verilmiştir. Ayrıca samimiyetle cevaplamalarının önemi ve 
araştırma sonuçlarına etkileri anlatılmıştır.

\section{Verilerin Analizi}

Bu araştırmada bağımlı ve bağımsız değişkenler arasındaki ilişkiyi açıklamak için çoklu regresyon analizi kullanılmıştır. Çoklu regresyon analizinin var-sayımlarını karşılamak için analiz öncesinde bazı işlemler yapılmıştır. Elde edilen verilerden 7'si çok sayıda kayıp veri içermesi dolayısıyla analiz dışı bırakıımıştı. Dağılımların normalliğini test etmek için yatay ve dikey çarpıklık değerleri dikkate alınmış; bütün değişkenler için skewness ve kurtosis değerlerinin -1 ve +1 arasında olduğu görülmüştür. Bu da verilerin normal dağıldığını göstermektedir. Sonuç olarak analizler 359 katılımcı üzerinden gerçekleştirilmiştir. Yukarıda sayılan tüm işlemler ve Pearson Çarpım Momentleri Analizi, Tek Faktörlü ANOVA ve adımsal (stepwise) çoklu regresyon analizi SPSS 22 programı ile yapılmıştır.

\section{Bulgular}

Araştırmanın bu kısmında giriş bölümünde bahsedilen araştırma sorularının yanıtları sırasıyla verilmiştir. Araştırmanın ilk amacı olan öz anlayış ile bağlanma stilleri arasındaki ilişkiyi incelemek ve değişkenler arasındaki ilişkiyi ortaya koymak için korelasyon analizi uygulanmıştır. Analiz sonuçlarına göre öz anlayış ile kaygılı bağlanma $(r=-.41, p<.001)$ ve kaçınmalı bağlanma ( $r=-.28, p<.001$ ) değişkenleri arasında negatif yönde anlamlı bir ilişki bulunmaktadır (bkz. Tablo 1).

Tablo 1. Öz Anlayış, Kaygılı Bağlanma ve Kaçınmalı Bağlanma Arasındaki ilişkiyi Belirlemek İçin Yapılan Pearson Momentler Çarpımı Analiz Sonuçları

\begin{tabular}{cccc}
\hline & Kaygılı Bağlanma & Kaçınmalı Bağlanma \\
\hline Öz Anlayış & $r$ & $-.41^{* *}$ & $-.28^{* *}$ \\
\hline${ }^{* *} \mathrm{p}<.001$ & & &
\end{tabular}

Araştırmanın ikinci amacı olan bağlanma stillerinin öz anlayış düzeyini yordayıp yordamadığını incelemek amacıyla hiyerarşik regresyon analizi yapılmıştır. İlgili R2 değerlerine göre ilk aşamada kaygılı bağlanma stilinden alınan puan, toplam varyansın \% 18'ini açıklayabilmektedir. Kaygıı bağlanma stilinin yordanan değişkenin (öz-anlayış) varyansına olan katkısı .001 düzeyinde, 1 ve 357 serbestlik derecesi ile anlamlıdır ( $F=75.64)$. İkinci aşamada kaygılı bağlanmanın kaçınmalı bağlanma ile birlikte varyansa olan katkısının \% 24'e yükseldiği görülmektedir. Kaygılı bağlanmanın kaçınmalı bağlanma ile birlikte .001 düzeyinde öz-anlayışı yordaması 1 ve 356 serbestlik derecesi ile anlamlıdır ( $F=55.92)$. Sonuçlar Tablo 2'de gösterilmiştir.

Tablo 2. Öz Anlayış Üzerinde Kaygılı ve Kaçınmalı Bağlanma Stillerinin Etkisini Belirlemeye Yönelik Yapılan Adımsal Regresyon Analizi Tablosu

\begin{tabular}{llccccc}
\hline Model & Değişkenler & $\beta$ & Standartlaştırılmış Hata & Standartlaştırılmış ß & $\mathrm{t}$ & $\mathrm{p}$ \\
\hline \multirow{2}{*}{ 11. Adım } & Sabit & 95.61 & 2.48 & -.418 & 38.55 &, 000 \\
& Genel Bilgi & 108.45 & 3.34 & & 32.43 &, 000 \\
\hline
\end{tabular}

$F=55.92 ; p<.001, R=.49 ; R 2=.24$

Bir diğer araştırma amacı olarak, öz-anlayış düzeyinin kişisel bilgi formunda yer alan yaş, cinsiyet, kardeş sayısı, ekonomik durum, ilişki durumu, akademik başarı ve psikolojik yardım alma durumları ile ilgili değişkenlere göre farklılaşıp farklılaşmadığını incelemek için tek yönlü ANOVA analizi yapılmıştır. Bu analiz sonucunda, öz-anlayışın yaş, cinsiyet, kardeş sayısı, ekonomik durum, akademik başarı ve psikolojik yardım alma durumlarına göre farklılaşmadığı tespit edilmiştir ( $p>$.05). Fakat öz-anlayış düzeyinin ilişki durumuna göre anlamlı düzeyde farklılık gösterdiği görüşmüştür. Bu farklılık, ilişkisi olan grup lehindedir $(F(1-339)=8.03, p<.01)$. ilişkisi olan grubun $(X=78.14, S S=14)$ ilişkisi olmayanlara göre $(X=73.26, S S=14.74)$ öz-anlayış düzeylerinin daha yüksek olduğu görülmüştür. Gruplar arası farklılık ve Tek Yönlü ANOVA sonuçları Tablo 3'de verilmiştir.

Tablo 3. Öz-Anlayış düzeylerinin ilişki durumuna göre farklııı̆ı

\begin{tabular}{lccccc}
\hline i̇lişki Durumu & X & SS & N & F & p \\
\hline İlişkisi var & 78.14 & 14 & 102 & 8.03 & .005 \\
illişkisi yok & 73.26 & 14.74 & 238 & & \\
\hline
\end{tabular}

Bir diğer araştırma amacı olarak, bağlanma stillerinin (kaygılı ve kaçınmalı bağlanma) kişisel bilgi formunda yer alan yaş, cinsiyet, kardeş sayısı, ekonomik durum, ilişki durumu, akademik başarı ve psikolojik yardım alma durumları ile ilgili 
değişkenlere göre farklılaşıp farklılaşmadığını incelemek için tek yönlü ANOVA analizi yapılmıştır. Bu analiz sonucunda, bağlanma stillerinin yaş, cinsiyet, kardeş sayısı, ekonomik durum, akademik başarı ve psikolojik yardım alma durumlarına göre farklılaşmadığı tespit edilmiştir ( $p>05$ ). Fakat kaçınmalı bağlama stilinin ilişki durumuna göre farklılık gösterdiği bulunmuştur $(F(1-339)=56.42, p<.001)$. ilişkisi olanların $(X=55.82, S S=18.63)$ ilişkisi olmayanlara göre $(X=70.75$, SS=15.94) kaçınmalı bağlanma skorlarının daha düşük olduğu görülmüştür. Bununla birlikte, kaygılı bağlanma stillerinin ilişki durumuna göre farklılaşmadığı bulgusuna ulaşılmıştır $(F(1-339)=1.02, p>.05)$. Gruplar arası farklılık ve Tek Yönlü ANOVA sonuçları Tablo 4'de verilmiştir.

Tablo 4. Bağlanma stillerinin ilişki durumuna göre farklıığı

\begin{tabular}{lccccc}
\hline ilişki Durumu & $\mathrm{X}$ & SS & $\mathrm{N}$ & $\mathrm{F}$ & $\mathrm{p}$ \\
\hline ilişkisi var & 55.82 & 18.63 & 102 & 56.42 & .000 \\
ilişkisi yok & 70.75 & 15.94 & 238 & & \\
\hline
\end{tabular}

\section{Sonuçlar}

Araştırmada elde edilen bulgular sonucunda; öz anlayış ile yakın ilişkilerde bağlanma stilleri arasında negatif yönde anlamlı bir ilişki olduğu görülmüştür. Yani bireylerin kaygılı bağlanma veya kaçınmalı bağlanma düzeyleri arttkça, öz anlayış düzeylerinde azalma olduğu sonucuna varılmıştr. Bununla birlikte, bağlanma stillerinin öz anlayış düzeyini yordayıp yordamadığı incelenmiş ve kaygılı ve kaçınmalı bağlanma stillerinin birlikte öz anlayışı önemli bir oranda açıkladığı görülmüştür. Ayrıca, öz-anlayış düzeyinin ve bağlanma stillerinin ayrı ayrı kişisel bilgi formunda yer alan yaş, cinsiyet, kardeş sayısı, ekonomik durum, ilişki durumu, akademik başarı ve psikolojik yardım alma durumları ile ilgili değişkenlere göre farklılaşıp farklılaşmadığı araştrıımış ve değişkenlerden yalnızca ilişki durumunda anlamlı düzeyde farklılaşma görülmüştür.

Bu araştırmada, ilişkideki bağlanma stillerinin öz-anlayışla yakın ilişki içinde olduğu ve güvenli bağlanmanın öz-anlayış ile pozitif bir ilişki içinde olduğu sonucuna varılmıştır. Literatürde öz-anlayış ile ilgili bu bulguyu destekleyen araştırmalar yer almaktadır. Öz-anlayış kavramını tanımlayarak alanyazına kazandıran Neff ve arkadaşlarının konu ile ilgili çeşitli araştırmaları bulunmaktadır. Kendine anlayışı yüksek olan insanlar, hatalar yaparken kendilerine karşı nazik ve anlayışlı davranırlar, tüm insanların kusurlu olduğunu fark eder, hata yapar ve hataları hakkında düşünmezler. Bunun aksine, kendine anlayışı az olan insanlar, hata yaparken kendileri için eleştirel olma eğilimi gösterirler, bu hataları yaparken benzersiz olduklarına inanırlar ve hatalarını takıntılı bir şekilde tespit ederler (Neff, 2003). Buradan yola çıkarak, kendine merhametin, kişisel hoşnutluğu arttırdığını söylemek mümkündür (Neff, ve Beretvas, 2013). Kendine daha fazla anlayış gösteren yakın arkadaşlar ise kendileri hakkında daha iyi hissedebilirler ve böylece kişilerarası ilişkilerinde daha fazla tatmin olabilirler. (Hendrick, Hendrick, ve Adler, 1988; Murray, Holmes, ve Griffin, 1996a).

Bağlanma biçimi öz anlayışı yordayan bir etkendir. Öz-anlayış güvenli bağlanma ile olumlu ilişki içinde iken, kaygılı ve kaçınmalı bağlanma ile olumsuz bir ilişki içinde çıkmıştı (Neff, 2003a; Neff ve McGehee, 2010; Neff, Pisitsungkagarn, ve Hseih, 2008). Neff ve McGehee (2010) genç yetişkinlerle yaptıkları çalışmada güvensiz bağlanma türleri ile (kaygılı ve kaçınmalı) öz anlayış arasında negatif bir ilişki olduğunu bulurken, bakıılların sürekli olarak mevcut olduğu ve gerektiğinde ilgi verdiği bir ortamda yetiştirilen bireylerin kendilerine şefkatli bir şekilde yaklaşma yeteneğini geliştirdiklerini belirtmişlerdir. Bunun nedenini, güvensiz bağlanan insanların onay alma için dış kaynaklara ihtiyaç duyması ve bu sebeple kendilerine karşı öz anlayışlı olabilmek için iç kaynaklarına ulaşmada ve iç kaynaklarını kullanmada zorlanmaları ile açıklamışlardır.

Yürütülen bu araştırmada, öz-anlayış ve güvenli bağlanmanın ilişkisine ek olarak bağlanma stillerinin öz-anlayışı açıklama derecesinin yüksek olduğu bulunmuştur. Bu bağlamda, kaygılı ve kaçınmalı bağlanmanın birbirinden ayrı olarak öz-anlayışı tahmin etmede önemli yere sahip olduğu söylenebilir. Raque-Bogdan, Ericson, Jackson, Martin ve Bryan (2011) araştırmalarında kaygılı ve kaçınmalı bağlanan kişilerin öz anlayışlarının düşük olduğunu ifade ederken, kaygılı bağlanan kişilerin kendilerine karşı nazik olma konusunda ve stresli olaylara farkındalıkla yaklaşmada zorlanabildiğini belirtmişlerdir. Bununla birlikte, Wei ve arkadaşları (2011) öz anlayış ile kaygılı ve kaçınmalı bağlanma arasındaki negatif ilişkiyi açıklarken, bağlanma kaygısı olanların, kendilerine karşı şefkatli olma olasılıklarının daha az olduğunu belirtmişlerdir. Bunun nedenini ise, zihinlerindeki olumsuz çalışma modellerinden ötürü kendilerine karşı şefkatli olamamaları ve olumsuz deneyimleri sadece kendi başlarına gelen yaşantılar olarak görmeleri (stresli durumları aşırı duygusallaştırma eğilimleri nedeniyle) ile açıklamışlardır. Kaçınmalı bağlanmanın ise hem gerçek yaşamda (örneğin, topluluk gönüllü faaliyetleriyle ilgili olarak) hem de laboratuvarda merhamet ve anlayış göstermemekle oldukça güçlü bir ilişki içinde olduğu görülmüştür (Gillath, Shaver, ve Mikulincer, 2005). 
Araştırma bulgularında ayrıca, bağlanma stillerinden kaçınmalı bağlanmanın ilişki durumuna göre anlamlı düzeyde farklılaştğı görülmüştür. Kaygıı bağlanmada anlamlı düzeyde bir farklılaşma görülmemiştir. Bu bulguya göre, ilişkisi olanların ilişkisi olmayanlara göre kaçınmalı bağlanma skorlarının daha düşük olduğu görülmüştür. Kaçınmalı bağlanma düzeyi düşük olan bireyler ilişkide daha güvenli hisse-derler. Dolayısıyla da bu araştrmada ilişkisi olan bireylerin ilişkisi olmayanlara göre daha güvenli bağlandıkları görülmüştür. Bu bulguyu destekleyecek literatürde çok sayıda araştrrma yer almaktadır (Akbağ ve İmamoğlu, 2010; Demirci-Yoraz ve Demir, 2009; Deniz ve ark., 2005; DiTommaso ve ark., 2003; IIlhan, 2012; Kobak ve Sceery, 1988). Kaçınmalı bağlanma stilline sahip kişilerin kendilerine dair algıları olumlu iken başkalarıyla ilgili algıları çoğunlukla olumsuzdur. Acı çekmekten kaçınan ve bu nedenle bağlanmaya dair yoğun kaygı yaşayan bu kişiler, yakın ilişkilerden rahatsız olurlar (Bartholomew ve Horowitz, 1991). Kobak ve Sceery (1998) tarafindan bağlanma stillerinde ilişki durumları ve yalnızlık durumları ile ilgili yürütülen araştırmaya göre, kaçınmalı bağlanmaya sahip bireylerin daha yalnız oldukları görülmüştür. Bu nedenle ilişkisi olan bireylerde daha düşük kaçınmalı bağlanmanın görüldüğü düşünülmektedir.

Son olarak, öz-anlayışın ilişki durumuna göre anlamlı düzeyde farklılaştığı görülmüştür. Bu bulguya göre, ilişkisi olan bireylerin ilişkisi olmayanlara göre daha yüksek öz-anlayışa sahip olduğu görülmüştür. Öz-anlayış ile ilgili yapılmış diğer araştırmalar bu bulguyu destekler niteliktedir. Öz anlayışa sahip bireylerin, öz anlayışı düşük olan bireylere göre, ilişkilerinde daha olumlu davranış gösterme eğiliminde oldukları gözlenmiştir. Öz anlayış puanları ayrıca ilişki doyumuyla da ilişki içinde çıkmıştır (Gilliath, Shaver ve Mikulincer, 2005). Güvensiz bir bağlanma şekline sahip olan bireylerin kaliteli bir ilişki deneyimlemede zorlandıkları belirtilmiştir. Kaygı ve kaçınmanın ilişki kalitesi üzerindeki farklı etkilerini inceleyen bir çalışmada, hem kaygı hem de kaçınmanın iliş̧i kalitesinin bilişsel, duygusal ve davranışsal yönlerini olumsuz etkilediği doğrulanmıştır (Li ve Chan, 2012). Shi (2003) tarafindan yürütülen araştırmada her iki yetişkin bağlanma boyutu (kaçınmalı ve kaygılı) romantik ilişkilerde, çatışma çözme davranışları ve ilişki doyumunun öngörücüleri olarak kabul edilmiştir. Bu çalışma, ben ve diğerleri hakkında olumlu algılamalara sahip olanların, her iki tarafin endişelerini de giderecek şekilde çaţşma çözme davranışlarını benimseme şansının yüksek olduğunu ortaya koymuştur. Buradan yola çıkılarak, ilişkisi olan bireylerin daha fazla öz anlayışa sahip olduğuna dair bulgular, öz anlayışın ilişkiyi sürdürmede yapııı bir etki yaratması ile açıklanabilir.

\section{5. Öneriler}

Bu çalışma, öz anlayış ve yakın ilişkilerde bağlanma arasındaki ilişkinin incelenmesi ve bu ilişkinin hangi değişkenlere göre farklılık gösterdiğinin araştırılması, öğrencilerin öz anlayış düzeyini artırması için müdahalede bulunma noktasında psikolojik danışmanlara ve psikologlara yardımcı niteliğinde olması açısından önemlidir. Araştırmanın sağlayacağı işlevsel ve somut bilgiler hangi noktalara müdahale edilmesi gerektiği konusunda bir fikir oluşturarak öz anlayış programlarının hazırlanmasına katkı sağlayabilir.

Literatür incelendiğinde rehberlik ve psikolojik danışmanlık alanında öz anlayış kavramına dair çok az çalışmanın olduğu ve yakın ilişkilerde bağlanma ile arasındaki ilişkinin incelenmesine yönelik yapılan araştırmaların sayıca yetersiz olduğu tespit edilmiştir. Bu nedenle, bu araştırma öz anlayış ve yakın ilişkilerde bağlanma arasındaki ilişkiyi ele alan bir çalışma olması anlamında önem taşır. Bu araştırma ileride yapılabilecek olan öz anlayış ve yakın ilişkilerde bağlanma stilleri ile ilgili farklı çalışmalara katkı sağlaması ve yeni bakış açıları sunması açısından da önem arz etmektedir.

\section{Kaynakça}

Akbağ, M., \& İmamoğlu, S. E. (2010). The prediction of gender and attachment styles on shame, guilt, and loneliness. Educational Sciences: Theory \& Practice, 10, 669-682.

Akın, A. (2009). Akılcı Duygusal Davranış̧̧ı Terapi (SDDT) odaklı grupla psikolojik danışmanın psikolojik iyi olma ve öz-duyarlık üzerindeki etkisi. Yayınlanmamış doktora tezi.

Bartholomew, K., \& Horowitz, L. M. (1991). Attachment styles among young adults: a test of a four-category model. Journal of personality and social psychology, 61(2), 226.

Bowlby, J. (1969). Attachment and Loss: Attachment; John Bowlby. Basic Books.

Brennan, K. A., Clark, C. L. \& Shaver, P. R. (1998). Self- Report measurement of adult attachment: An integrative overview. J. A. Simpson ve W. S. Rholes, (Ed.), Attachment theory and close relationships içinde (46-76). NY: Guilford Press.

Bretherton, I. (1985). Attachment theory: Retrospect and prospect. Monographs of the society for research in child development, 3-35.

Cassidy, J. (1994). Emotion regulation: Influences of attachment relationships. Monographs of the society for research in child development, 59(2-3), 228-249.

| Kastamonu Eğitim Dergisi, 27(3), 2019| 
Chopik, W. J., Edelstein, R. S., \& Fraley, R. C. (2013). From the cradle to the grave: Age differences in attachment from early adulthood to old age. Journal of personality, 81(2), 171-183.

Chow, C. M., \& Ruhl, H. (2014). Friendship and romantic stressors and depression in emerging adulthood: Mediating and moderating roles of attachment representations. Journal of Adult Development, 21(2), 106-115.

Creswell, J. W. (2013). Research design: Qualitative, quantitative, and mixed methods approaches. Los Angeles: Sage Publications.

Demirci-Yoraz, A. ve Demir, A. (2009). Cinsiyetin, bağlanma tipinin ve aile yapısının üniversite öğrencilerinin yalnızlık düzeyleri üzerindeki rolü. 10. Ulusal Psikolojik Danışma ve Rehberlik Kongresi'nde sunulan bildiri, Adana.

Deniz, M. E., \& Sümer, A. S. (2010). Farklı öz-anlayış düzeylerine sahip üniversite öğrencilerinde depresyon, anksiyete ve stresin değerlendirilmesi. Eğitim ve Bilim, 35(158).

Deniz, M., Kesici, Ş., \& Sümer, A. S. (2008). The validity and reliability of the Turkish version of the Self-Compassion Scale. Social Behavior and Personality: an international journal, 36(9), 1151-1160.

Deniz, M. E., Hamarta, E., \& ArI, R. (2005). An investigation of social skills and loneliness levels of university students with respect to their attachment styles in a sample of Turkish students. Social Behavior and Personality, 33 (1), 19-32.

DiTommaso, E., Brannen-McNulty, C., Ross, L., \& Burgess, M. (2003). Attachment styles, social skills and loneliness in young adults. Personality and Individual Differences, 35(2), 303-312.

Edelstein, R. S., Alexander, K. W., Shaver, P. R., Schaaf, J. M., Quas, J. A., Lovas, G. S., \& Goodman, G. S. (2004). Adult attachment style and parental responsiveness during a stressful event. Attachment \& Human Development, 6(1), 31-52.

Germer, C. K. (2009). The mindful path to self-compassion: Freeing yourself from destructive thoughts and emotions. Hove: Routledge.

Gilbert, P., \& Irons, C. (2009). Shame, self-criticism, and self-compassion in adolescence. Adolescent emotional development and the emergence of depressive disorders, 195-214.

Gillath, O., Shaver, P. R., \& Mikulincer, M. (2005). An attachment-theoretical approach to compassion and altruism. In P. Gilbert (Ed.), Compassion: Conceptualizations, research, and use in psychotherapy. London: Brunner-Routledge.

Kirkpatrick, K. L. (2005). Enhancing self-compassion using a Gestalt two-chair intervention (Doctoral dissertation).

Kobak, R. R., \& Sceery, A. (1988). Attachment in late adolescence: Working models, affect regulation, and representations of self and others. Child development, 135-146.

Hendrick, S. S., Hendrick, C., \& Adler, N. L. (1988). Romantic relationships: Love, satisfaction, and staying together. Journal of Personality and Social Psychology, 54(6), 980.

İlhan, T. (2012). Üniversite öğrencilerinde yalnızlık: cinsiyet rolleri ve bağlanma stillerinin yalnızlığı yordama güçleri. Educational Sciences: Theory \& Practice, 12(4), 2377-2396.

Leary, M. R., Tate, E. B., Adams, C. E., Batts Allen, A., \& Hancock, J. (2007). Self-compassion and reactions to unpleasant self-relevant events: the implications of treating oneself kindly. Journal of personality and social psychology, 92(5), 887.

Li, T., \& Chan, D. K. S. (2012). How anxious and avoidant attachment affect romantic relationship quality differently: A meta-analytic review. European Journal of Social Psychology, 42(4), 406-419.

Mallinckrodt, B., \& Chen, E. C. (2004). Attachment and interpersonal impact perceptions of group members: A social relations model analysis of transference. Psychotherapy Research, 14(2), 210-230.

Murray, S. L., Holmes, J. G., \& Griffin, D. W. (1996). The benefits of positive illusions: Idealization and the construction of satisfaction in close relationships. Journal of personality and social psychology, 70(1), 79.

Neuman, L. W. (2007). Basics of social research: qualitative and quantitative approach. USA: Pearson Education.

Neff, K. D. (2003a). The development and validation of a scale to measure self-compassion. Self and Identity, 2, 223-250.

Neff, K. D. (2003b). Self-compassion: an alternative conceptualization of a healthy attitude toward oneself. Self and Identity, 2, 85-102.

Neff, K. D. (2011). Self-compassion, self-esteem, and well-being. Social and personality psychology compass, 5(1), 1-12.

Neff, K. D., \& Beretvas, S. N. (2013). The role of self-compassion in romantic relationships. Self and Identity, 12(1), 78-98.

Neff, K. D., Hsieh, Y., \& Dejitterat, K. (2005). Self-compassion, achievement goals, and coping with academic failure. Self and Identity, $4(3), 263-287$.

Neff, D., Kirkpatrick, K., \& Rude, S. S. (2007), "Self-compassion and its link to adaptive psychological functioning". Journal of Research in Personality, 41, 139-154.

Neff, K. D., \& McGehee, P. (2010). Self-compassion and psychological resilience among adolescents and young adults. Self and Identity, 9, 225-240.

Neff, K. D., Pisitsungkagarn, K., \& Hsieh, Y. P. (2008). Self-compassion and self-construal in the United States, Thailand, and Taiwan. Journal of Cross-Cultural Psychology, 39(3), 267-285.

Özyeşil, Z. (2011). Üniversite öğrencilerinin öz-anlayış düzeylerinin bilinçli farkındalık kişilik özellikleri ve bazı değişkenler açısından incelenmesi (Doctoral dissertation, Selçuk Üniversitesi Eğitim Bilimleri Enstitüsü).

Raque-Bogdan, T. L., Ericson, S. K., Jackson, J., Martin, H. M., \& Bryan, N. A. (2011). Attachment and mental and physical health: self-compassion and mattering as mediators. Journal of Counseling Psychology, 58(2), 272. 
Shaver, P., \& Hazan, C. (1987). Being lonely, falling in love. Journal of Social Behavior and Personality, 2(2), 105.

Shi, L. (2003). The association between adult attachment styles and conflict resolution in romantic relationships. American Journal of Family Therapy, 31(3), 143-157.

Sümer, A. S. (2008). Farklı öz-anlayış (self-compassion) düzeylerine sahip üniversite öğrencilerinde depresyon anksiyete ve stresin değerlendirilmesi (Doctoral dissertation, Selçuk Üniversitesi Sosyal Bilimler Enstitüsü).

Sümer, N. (2006). Yetişkin bağlanma ölçeklerinin kategoriler ve boyutlar düzeyinde

karşılaştırılması. Türk Psikoloji Dergisi, 21(57), 1-22.

Wei, M., Liao, K. Y. H., Ku, T. Y., \& Shaffer, P. A. (2011). Attachment, self-compassion, empathy, and subjective well-being among college students and community adults. Journal of personality, 79(1), 191-221.

Zhang, H. (2012). Self-improvement as a response to interpersonal regulation in close relationships: The role of attachment styles. The Journal of social psychology, 152(6), 697-712. 